\title{
Assessment of Safe Cartilage Harvesting Quantity in the Shoulder: A Cadaveric Study
}

\author{
Michael C. O’Brien, B.S., M.A., Wojciech K. Dzieza, B.S., Michelle L. Bruner, M.S., and \\ Kevin W. Farmer, M.D.
}

\begin{abstract}
Purpose: To evaluate the volume and yield of morselized cartilage that can be harvested from the shoulder for immediate reimplantation and repair. Methods: A standard arthroscopic approach was used to harvest non-load-bearing cartilage from 5 cadaveric shoulder specimens. Cartilage was separated from the humerus, grasped, added to the cartilage particulator, and morselized to form a cartilage paste. The volume of reclaimed cartilage was measured and compared with average humeral and glenoid defects. Results: The total yield of cartilage paste following tissue processing that was obtained from the 5 glenohumeral joints ranged from $1.0 \mathrm{~mL}$ to $2.4 \mathrm{~mL}$ with a mean volume of $1.9 \pm 0.5 \mathrm{~mL}$, yielding a theoretical $18.6 \mathrm{~cm}^{2} \pm 5.2 \mathrm{~cm}^{2}$ of coverage with a 1-mm monolayer. Previously reported mean glenoid defect size ranges from $1.12 \mathrm{~cm}^{2}$ to $2.73 \mathrm{~cm}^{2}$, while the mean humeral defect size ranges from $4.22 \mathrm{~cm}^{2}$ to $6.00 \mathrm{~cm}^{2}$. Conclusions: This study validated that through a single-stage surgical and processing technique it is possible to obtain a sufficient volume for re-implantable autologous morselized cartilage graft to address most glenohumeral articular cartilage defects. Clinical Relevance: Chondrocyte grafts have been shown to be effective in cartilage repair. A single-site, single-staged procedure that uses a patient's autologous shoulder cartilage from the same joint has the potential to reduce morbidity associated with multiple surgical sites, multistaged procedures, or nonautologous tissue in shoulder surgery.
\end{abstract}

A rticular cartilage defects of the glenohumeral joint occur less frequently in the general population compared with weight-bearing joints such as the hip, knee, or ankle. While glenohumeral chondral defects are generally a problem of the aging population, commonly arising from previous or concomitant shoulder trauma, glenohumeral instability, or postoperative chondrolysis, ${ }^{1}$ they are becoming a more common problem in the young and active population, with an incidence ranging from $5 \%$ to $17 \% .^{2,3}$ Chondral defects are often missed on magnetic resonance imaging and are usually

From the Department of Orthopaedics $\theta$ Rehabilitation (M.C.O, W.K.D., M.L.B., K.W.F.) and College of Medicine (M.C.O., W.K.D.), University of Florida, Gainesville, Florida, U.S.A.

The authors report the following potential conflicts of interest or sources of funding: M.C.O., W.K.D., M.L.B., and K.W.F. report nonfinancial support from Exactech during the conduct of the study. K.W.F reports consultancy with Exactech. Full ICMJE author disclosure forms are available for this article online, as supplementary material.

Received January 31, 2020; accepted August 15, 2020.

Address correspondence to Kevin W. Farmer, M.D., P.O. Box 112727, Gainesville, FL 32611-2727. E-mail: farmekw@ortho.ufl.edu

(C) 2020 THE AUTHORS. Published by Elsevier Inc. on behalf of the Arthroscopy Association of North America. This is an open access article under the CC BY-NC-ND license (http://creativecommons.org/licenses/by-nc-nd/4.0/). 2666-061X/2089

https://doi.org/10.1016/j.asmr.2020.08.016 incidental findings during diagnostic arthroscopy for another shoulder injury, such as rotator cuff tear or labral tear. ${ }^{4-7}$ These defects occasionally become symptomatic, warranting further management. ${ }^{2,4}$

Many variables come into play when approaching the treatment of articular cartilage defects of the glenohumeral joint in the young, active population. A dilemma in treatment arises from the inability of the body to heal optimally due to the lack of blood supply to the articular cartilage. ${ }^{8}$ If left untreated, these lesions may progress to glenohumeral osteoarthritis, causing a long-term negative impact on the patient's function and quality of life. Total shoulder arthroplasty has been shown to be effective in relieving pain from articular cartilage defects; however, its application in the younger population is not a favorable choice due to the limited durability of the replaced joint. ${ }^{1,2}$ This has led to the development of various surgical options to better target cartilage defects in a less-invasive manner.

Several surgical techniques are now available for the management of articular cartilage defects of the glenohumeral joint, including arthroscopic debridement, microfracture, osteochondral autograft transplantation, allograft transplantation, and autologous chondrocyte implantation (ACI) or matrix-induced autologous chondrocyte implantation (MACI). Currently, there is 


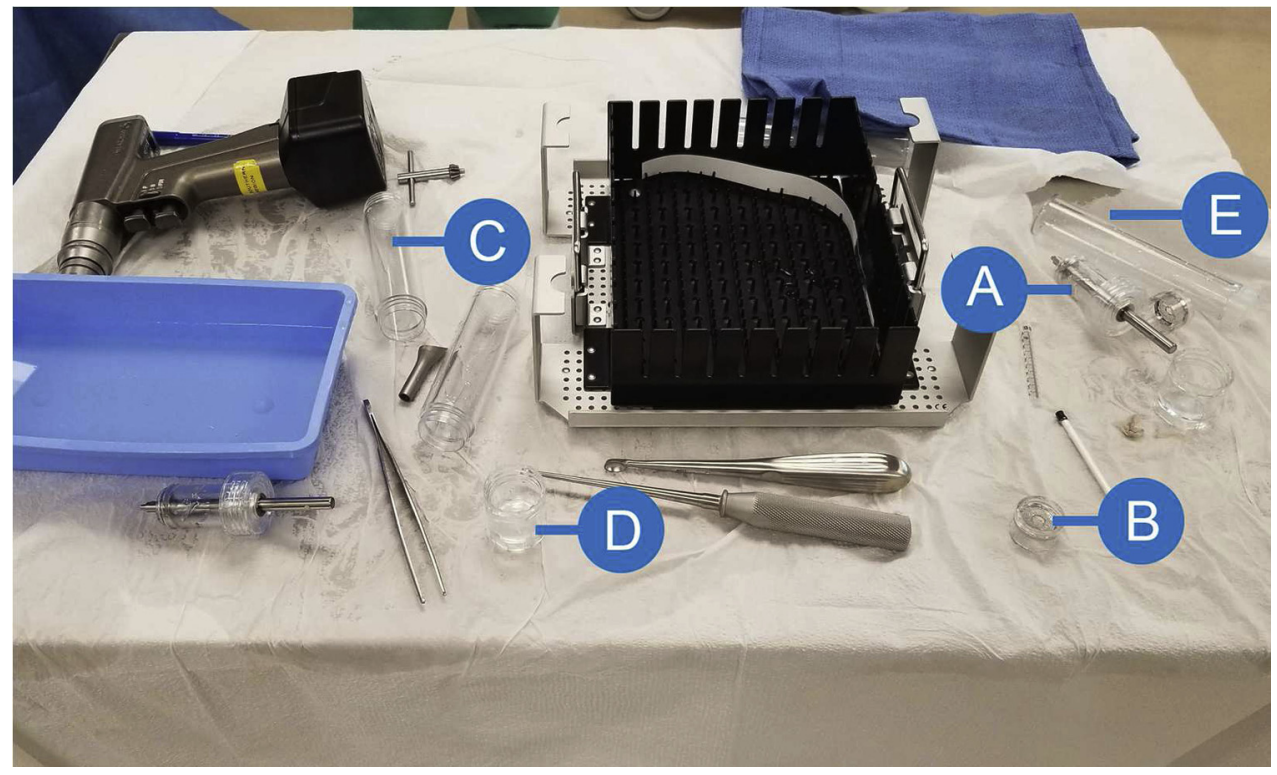

Fig 1. Reveille CP System. Cartilage particulator device components used in the study. (A) Particulator. (B) Tissue holder. (C) Collection tube. (D) Tissue collection cup. (E) Filtration tube.

no clear consensus on which technique provides the best outcome in the glenohumeral joint, given the paucity of studies on long-term outcomes. ${ }^{2,4,9,10}$ In addition, these techniques are not without individual drawbacks, such as multiple surgical sites, multistaged procedures, high cost, or nonautologous tissue. ${ }^{1,2,4}$
Fig 2. Arthroscopic view from the posterior portal of left shoulder demonstrating cartilage harvesting from the superior humeral head adjacent to the rotator cuff insertion.

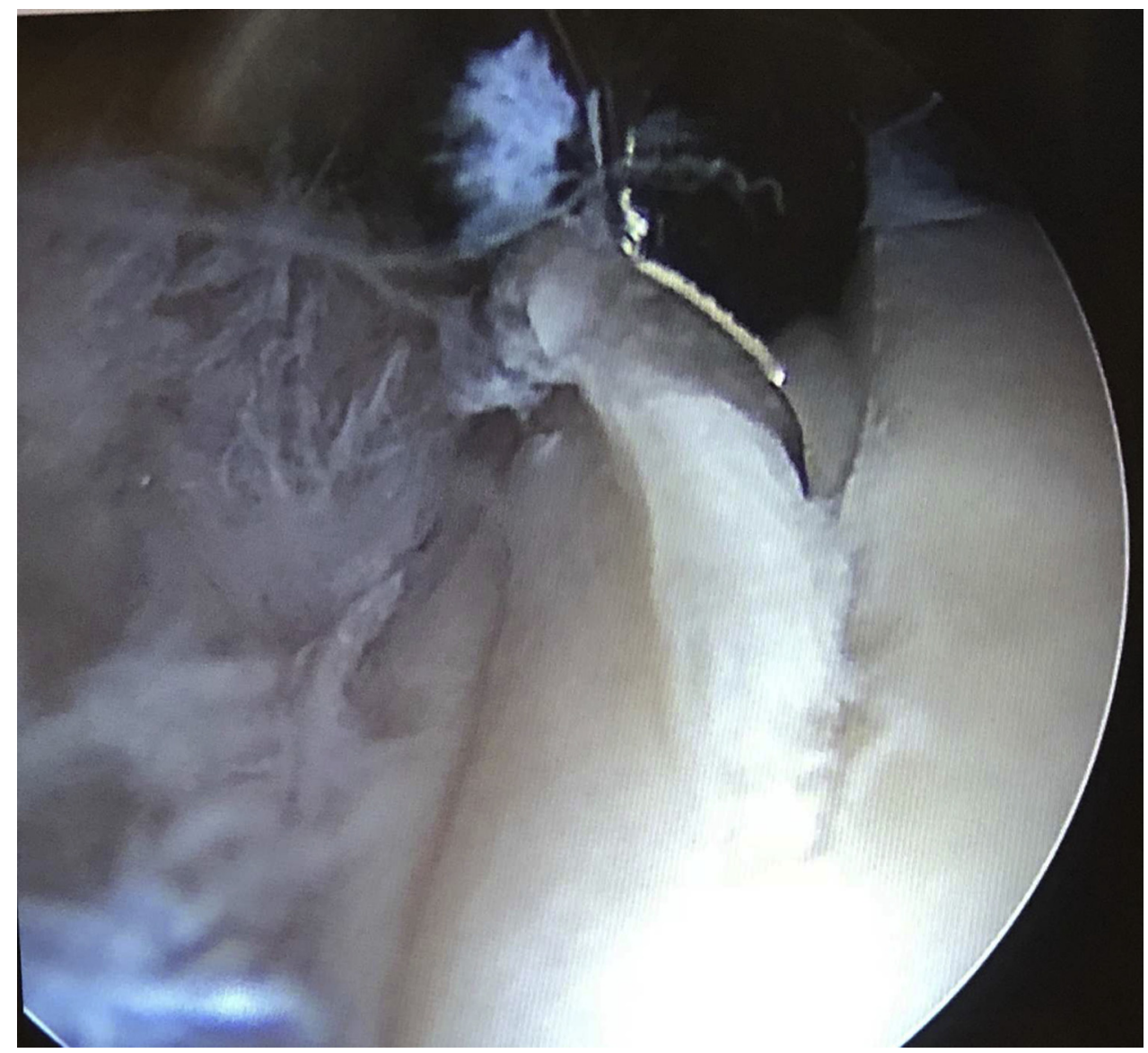




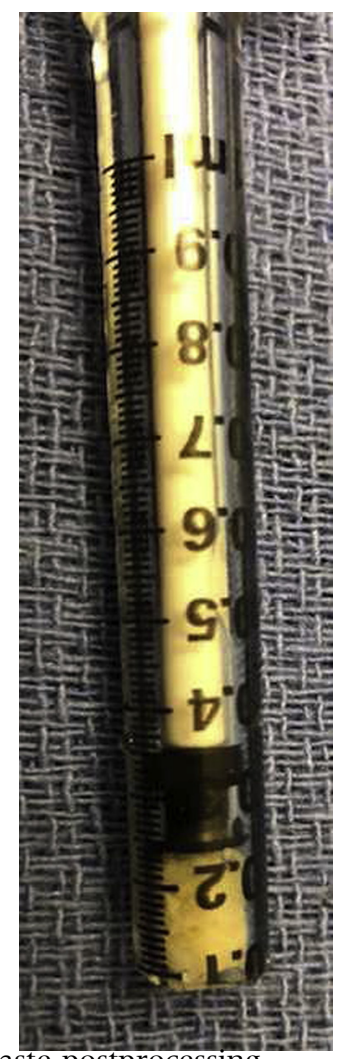

Fig 3. Cartilage paste postprocessing.

An innovative approach that applies the principle of new tissue formation for cartilage injuries has been applied in the knee $^{11}$ and shown to be effective ${ }^{12}$; however, the amount of tissue that can be reclaimed from intraoperative, autologous, glenohumeral harvesting has not been demonstrated. This approach allows for harvesting of cartilage from the non-loadbearing area in the joint, morselizing it, and applying it over the defect. Reveille CP (Exactech Inc., Gainesville, FL) (Fig 1) is a device that applies the principle of increasing surface area of cartilage particles to promote cartilage regeneration and prepares tissue grafts for immediate reimplantation. The aim of this study was to evaluate the volume and yield of morselized cartilage that can be harvested from the shoulder for immediate reimplantation and repair. We hypothesized that the amount of cartilage obtained would be sufficient to cover average sized defects of the glenoid and humerus.

\section{Methods}

This study was approved by the University of Florida Institutional Review Board (\#201800819). Five healthy cadaveric shoulder specimens were obtained from MedCure (Portland, OR), stored in a $-25.5^{\circ} \mathrm{C}$ freezer for an average of 7 days, and were thawed in a $4^{\circ} \mathrm{C}$ fridge over the course of 2 days before cartilage harvest. All 5 specimens were operated on by a single boardcertified, fellowship-trained orthopaedic surgeon according to the procedure outlined to follow. Specimens were excluded if they demonstrated advanced arthritis. Patient demographic data were not available.

\section{Technique}

A standard diagnostic arthroscopy was performed on each cadaveric specimen to identify significant osteoarthritis or any pre-existing anatomic shoulder pathology. Direct visualization of the maximum end-range of shoulder flexion, extension, and abduction was directly observed arthroscopically to determine non-loadbearing cartilage. Cartilage was then harvested from the superior aspect of the humeral head medial to the insertion of the rotator cuff that did not demonstrate significant articulation during arthroscopic end range of motion testing. The cartilage was separated from the humerus with a curette in a medial to lateral direction starting adjacent to the insertion of the rotator cuff and long head of the biceps tendon (Fig 2). Graspers were used to retrieve and remove the cartilage flap from the anterior portal. The cartilage was added directly to the Reveille cartilage particulator to diminish fragment loss from the transfer. These steps were repeated until further harvest was no longer possible through arthroscopic means. The particulator was threaded onto a drill and tissue was morselized for at least 2 minutes at $1500 \mathrm{rpm}$. The total volume of processed cartilage reclaimed was measured using a syringe demarcated in 0.1-mL increments (Fig 3).

\section{Outcomes of Interest and Analysis}

The primary outcome of interest was volume of postprocessed cartilage (milliliters) that could be reclaimed from healthy cadaveric specimens. The theoretical size of a defect that could be covered with the reclaimed amount of cartilage paste was calculated using the theoretical cartilage defect coverage formula (Fig 4). The extrapolated mean from the samples was

$$
\text { defect size }\left(\mathrm{cm}^{2}\right)=\frac{\text { cartilage paste }\left(\mathrm{cm}^{3}\right)}{\text { layer thickness }(0.1 \mathrm{~cm})}
$$

Fig 4. Theoretical cartilage defect coverage formula. The formula used to estimate the theoretical size of a defect that could be covered with the reclaimed amount of cartilage paste assuming a target l-mm monolayer. 
Table 1. Amount of Cartilage Paste Available for Transfer

\begin{tabular}{lcc}
\hline Sample No. & $\begin{array}{c}\text { Volume of } \\
\text { Cartilage After } \\
\text { Processing, } \mathrm{mL}\end{array}$ & $\begin{array}{c}\text { Theoretical } \\
\text { Defect Size } \\
\text { Coverage, } \mathrm{cm}^{2}\end{array}$ \\
\hline 1 & 2.4 & 24 \\
2 & 1.0 & 10 \\
3 & 2.0 & 20 \\
4 & 2.0 & 20 \\
5 & 1.9 & 19 \\
Mean \pm standard deviation & $1.9 \pm 0.5$ & $18.6 \pm 5.2$ \\
\hline NOTE. Volume of cartilage paste following processing is reported for \\
each specimen. Corresponding theoretical defect size coverage using \\
formula from Figure 4 reported for each specimen.
\end{tabular}

compared with the mean estimated or calculated size of humeral head and glenoid defects reported in the literature.

\section{Results}

The total yield of cartilage paste following tissue processing that was obtained from the 5 glenohumeral joints ranged from $1.0 \mathrm{~mL}$ to $2.4 \mathrm{~mL}$ with a mean volume of $1.9 \mathrm{~mL}$ (Table 1 ).

\section{Discussion}

This cadaveric study demonstrated that adequate cartilage can be harvested to cover average and above average-sized defects of the glenoid and humerus in the shoulder. Using the conversion formula (Fig 4), our results demonstrate that the average volume of reclaimed processed cartilage yields $18.6 \mathrm{~cm}^{2}$ of coverage. According to the literature, the mean glenoid defect size ranges from 1.12 to $2.73 \mathrm{~cm}^{2}$, whereas the mean humeral defect size ranges from 4.22 to $6.00 \mathrm{~cm}^{2}$ (Table 2). 3,13-16 The mean articular cartilage depth of the humerus has been reported to be $1.24 \mathrm{~mm}$, ranging from approximately $1.3 \mathrm{~mm}$ centrally and thinning to less than $1 \mathrm{~mm}$ along the periphery, and the mean depth of the glenoid fossa has been reported to be $1.88 \mathrm{~mm}^{.17}$

Regeneration of lost cartilage has been the ultimate goal for treatment of articular cartilage defects of the glenohumeral joint. While based on this general principle, the various approaches to surgical management of glenohumeral articular defects currently available focus on regenerating articular cartilage through different mechanisms. In microfracture, access to underlying bone marrow is made to allow for the mesenchymal stem cells, growth factors, fibrin, and platelets to organize into a fibrous clot. ${ }^{1,4}$ This technique has shown good results for small lesions but may lead to fibrocartilage buildup, with limited efficacy for larger lesions and poor long-term results..$^{3,13,14,18}$ In an osteochondral autograft procedure, osteochondral autograft plugs consisting of bone and cartilage are harvested, often from the knee, are then transferred and applied onto the defect. ${ }^{19,20}$ However, a common complication is harvest-site morbidity. ${ }^{1}$ Osteochondral allograft transfers have primarily been used to repair large humeral head defects. ${ }^{15,21,22}$ This technique has been limited by graft resorption, rare disease transmission, and questionable chondrocyte viability. ${ }^{22,23}$ While primarily investigated for repair of cartilage defects in the knee joint, ACI and MACI have shown promising results and potential for treatment in the shoulder. In ACI, a sample of cartilage from the edge of the defect is collected and expanded ex vivo for 3 to 4 weeks. The cells are then implanted into the defect in hopes of regenerating the missing cartilage. MACI follows the same principle as ACI with the use of a custom autologous chondrocyte-infused implant. Both ACI and MACI are limited by the need for multiple surgeries and time for the chondrocytes to grow exogenously, delaying definitive treatment. In addition, these novel techniques are not without the negative aspects of greater costs and limited donor resources. ${ }^{1,4,15,24,25}$

None of these techniques offer a single-site, singlestaged procedure that uses a patient's autologous cartilage. To date, same-joint cartilage harvest and application has only been done in the knee. ${ }^{11,12}$ Massen et al. ${ }^{12}$ reported satisfactory outcomes at 2-year follow-up in their cohort that underwent autologous minced cartilage transfer for chondral and osteochondral lesions in the knee. While the cohort was small, the authors concluded that it was a safe and cost-effective option in comparison with the other surgical techniques available. While this technique has not yet been studied clinically in the shoulder, it is reasonable to assume that it would also be associated with lower costs and no significant difference in morbidity when compared with other procedures.

Table 2. Summary of Average Glenohumeral Defect Sizes in the Published Literature

\begin{tabular}{|c|c|c|c|c|}
\hline Source & $\begin{array}{l}\text { Isolated Versus } \\
\text { Combined Lesion }\end{array}$ & Glenoid Defect Size & Humeral Defect Size & Sample Size \\
\hline Wang et al., $2018^{14}$ & Isolated & $1.53 \mathrm{~cm}^{2}$ (range, $1.00-3.75 \mathrm{~cm}^{2}$ ) & $5.20 \mathrm{~cm}^{2}$ (range, $4.00-7.80 \mathrm{~cm}^{2}$ ) & $\mathrm{n}=14$ \\
\hline Camp et al., $2015^{16}$ & Isolated & $1.12 \mathrm{~cm}^{2}$ & - & $\mathrm{n}=1$ \\
\hline Frank et al., $2010^{3}$ & Isolated & $1.66 \mathrm{~cm}^{2}$ (range, $0.40-3.75 \mathrm{~cm}^{2}$ ) & $5.07 \mathrm{~cm}^{2}$ (range, $1.0-7.84 \mathrm{~cm}^{2}$ ) & $\mathrm{n}=14$ \\
\hline \multirow[t]{2}{*}{ Millet et al., $2009^{13}$} & Isolated & $1.37 \mathrm{~cm}^{2}$ (range, $0.25-4.0 \mathrm{~cm}^{2}$ ) & $4.22 \mathrm{~cm}^{2}$ (range, $1.00-16.0 \mathrm{~cm}^{2}$ ) & $\mathrm{n}=25$ \\
\hline & Combined & $2.73 \mathrm{~cm}^{2}$ (range, $0.80-12.0 \mathrm{~cm}^{2}$ ) & $4.42 \mathrm{~cm}^{2}$ (range, $1.20-12.0 \mathrm{~cm}^{2}$ ) & $\mathrm{n}=6$ \\
\hline
\end{tabular}


Due to the avascular nature of cartilage tissue, the absorption of anabolic factors into the extracellular matrix is entirely dependent upon diffusion, which is limited by available surface area of the tissue. With increased surface area, bioactive factors present in minced cartilage grafts are better able to interact with marrow elements, such as mesenchymal stem cells, recruited to the lesion without the need to grow chondrocytes ex vivo. ${ }^{26-29}$ Tissue grafts prepared with Reveille CP (Exactech Inc.) are composed primarily of tissue particles between $0.3 \mathrm{~mm}$ and $1.0 \mathrm{~mm}$ in diameter, representing a 10 -fold increase in surface area over that of intact articular cartilage, with exposure of cells on the surface of the particles. Fluorescent microscopy analysis has demonstrated high cellular viability in graft fragments following processing with Reveille CP. To avoid cartilage hypertrophy, a theoretical 1-mm layer of cartilage paste should be applied to a defect to imitate the true thickness of overlying cartilage, given limited subchondral bone involvement (Exactech internal study; data on file at Exactech). By use of the theoretical formula (Fig 4), the average volume of processed cartilage reclaimed in this study yielded enough cartilage paste for defect coverage. Even with large thickness subchondral defects or as high as $50 \%$ paste loss due to intraoperative transfer, this technique yields enough quantity of cartilage paste to fill glenoid or humeral defects similar in size to the previously reported averages in the literature. Thus, for typical glenoid or humeral cartilage defects, it would be reasonable to consider intraoperative cartilage reclamation with subsequent grafting as another technique for repair. Given the benefit of a single-stage and singlesite procedure, this novel technique demonstrates significant potential as a future treatment option for glenohumeral cartilage defects.

\section{Future Directions}

These results warrant further studies to assess clinical practicality and outcomes for routine use. Currently, it is up to the experience and judgment of the surgeon to determine the acceptable and safe area of cartilage harvest in the humeral head. Development of a sterile device capable of drawing a physical line across cartilage would help better delineate the non-load-bearing zone of articular cartilage. As a result, this would maximize cartilage reclamation and patient safety in the application of this technique. In addition, the development of techniques or medical devices that optimize placement of the thin layer of processed cartilage could maximize filling capacity and further improve the potential of this procedure. Finally, the development of a definitive treatment protocol to obtain cartilage for immediate reimplantation will improve the time and cost-effectiveness associated with glenohumeral cartilage defects.

\section{Limitations}

This study is not without its limitations. First, the demographics of the 5 cadaver specimens were not available; therefore, variability in death, duration of storage, cartilage degeneration since time of death, mechanism of death, and functional status of the shoulder while alive could not be determined. However, all specimens were noted to have minimal-to-no osteoarthritis and deemed appropriate candidates for cartilaginous repair. The study's small sample poses a limitation as well; it is unknown how well this process could be replicated on a larger number of shoulders, particularly given the potential variability in the amount of cartilage that can be harvested without adverse outcomes. However, studies have demonstrated that the medialization of the rotator cuff footprint up to $10 \mathrm{~mm}$ leads to acceptable clinical outcomes during rotator cuff repair. ${ }^{30,31}$ Based on this information, the harvest was performed just medial to the rotator cuff insertion and did not exceed more than 10 $\mathrm{mm}$ medial from that point. We theorize similarly acceptable outcomes with this technique. Finally, creating a uniform $1 \mathrm{~mm}$-thick layer during the grafting process may be challenging from a technical standpoint, thus overestimating the volume of cartilage paste actually needed for the procedure.

\section{Conclusions}

This study validated that through a single-stage surgical and processing technique it is possible to obtain a sufficient volume of reimplantable autologous morselized cartilage graft to address most glenohumeral articular cartilage defects.

\section{Acknowledgments}

The authors thank Chris Koenig for coordinating cadaver procurement, Thien Doan for Exactech support and consultation, and Thiago Love-Leonor for Exactech device and surgical tech support during the trial.

\section{References}

1. Saltzman BM, Leroux T, Cole BJ. Management and surgical options for articular defects in the shoulder. Clin Sports Med 2017;36:549-572.

2. Fiegen A, Leland DP, Bernard CD, et al. Articular cartilage defects of the glenohumeral joint: A systematic review of treatment options and outcomes [published online August 23, 2019]. Cartilage. https://doi.org/10.1177/1947 603519870858.

3. Frank RM, Van Thiel GS, Slabaugh MA, Romeo AA, Cole BJ, Verma NN. Clinical outcomes after microfracture of the glenohumeral joint. Am J Sports Med 2010;38: 772-781.

4. Seidl AJ, Kraeutler MJ. Management of articular cartilage defects in the glenohumeral joint. J Am Acad Orthop Surg 2018;26:e230-e237. doi:10.5435/JAAOS-D-17-00057. 
5. Guntern DV, Pfirrmann CWA, Schmid MR, et al. Articular cartilage lesions of the glenohumeral joint: Diagnostic effectiveness of MR arthrography and prevalence in patients with subacromial impingement syndrome. Radiology 2003;226:165-170.

6. Denti M, Monteleone M, Trevisan C, De Romedis B, Barmettler F. Magnetic resonance imaging versus arthroscopy for the investigation of the osteochondral humeral defect in anterior shoulder instability. A doubleblind prospective study. Knee Surg Sports Traumatol Arthrosc 995;3:184-186.

7. Yeh LR, Kwak S, Kim YS, et al. Evaluation of articular cartilage thickness of the humeral head and the glenoid fossa by MR arthrography: Anatomic correlation in cadavers. Skeletal Radiol 1998;27:500-504.

8. Becerra J, Andrades JA, Guerado E, Zamora-Navas P, López-Puertas JM, Reddi AH. Articular cartilage: Structure and regeneration. Tissue Eng Part B Rev 2010;16: 617-627.

9. Gross CE, Chalmers PN, Chahal J, et al. Operative treatment of chondral defects in the glenohumeral joint. Arthrosc J Arthrosc Relat Surg 2012;28:1889-1901.

10. DePalma AA, Gruson KI. Management of cartilage defects in the shoulder. Curr Rev Musculoskelet Med 2012;5: 254-262.

11. Salzmann GM, Calek A-K, Preiss S. Second-generation autologous minced cartilage repair technique. Arthrosc Tech 2017;6:e127-e131.

12. Massen FK, Inauen CR, Harder LP, Runer A, Preiss S, Salzmann GM. One-step autologous minced cartilage procedure for the treatment of knee joint chondral and osteochondral lesions: A series of 27 patients with 2-year follow-up. Orthop J Sports Med 2019;7:232596711985377.

13. Millett PJ, Huffard BH, Horan MP, Hawkins RJ, Steadman JR. Outcomes of full-thickness articular cartilage injuries of the shoulder treated with microfracture. Arthroscopy 2009;25:856-863.

14. Wang KC, Frank RM, Cotter EJ, et al. Long-term clinical outcomes after microfracture of the glenohumeral joint: Average 10-year follow-up. Am J Sports Med 2018;46: 786-794.

15. Buchmann S, Salzmann GM, Glanzmann MC, Wörtler K, Vogt S, Imhoff AB. Early clinical and structural results after autologous chondrocyte transplantation at the glenohumeral joint. J Shoulder Elbow Surg 2012;21: 1213-1221.

16. Camp CL, Barlow JD, Krych AJ. Transplantation of a tibial osteochondral allograft to restore a large glenoid osteochondral defect. Orthopedics 2015;38:el47-e152.

17. Fox JA, Cole BJ, Romeo AA, et al. Articular cartilage thickness of the humeral head: An anatomic study. Orthopedics 2008;31:216.
18. Hünnebeck SM, Magosch P, Habermeyer P, Loew M, Lichtenberg S. Chondral defects of the glenohumeral joint: Long-term outcome after microfracturing of the shoulder. Obere Extrem 2017;12:165-170.

19. Wyland DJ, Beicker C. Osteochondral autograft transfer technique for glenoid osteochondral defect. Arthrosc Tech 2016;5:e965-e970.

20. Kircher J, Patzer T, Magosch P, Lichtenberg S, Habermeyer P. Osteochondral autologous transplantation for the treatment of full-thickness cartilage defects of the shoulder: Results at nine years. J Bone Joint Surg $\mathrm{Br}$ 2009;91-B:499-503.

21. Riff AJ, Yanke AB, Shin JJ, Romeo AA, Cole BJ. Midterm results of osteochondral allograft transplantation to the humeral head. J Shoulder Elbow Surg 2017;26:e207-e215.

22. Saltzman BM, Riboh JC, Cole BJ, Yanke AB. Humeral head reconstruction with osteochondral allograft transplantation. Arthroscopy 2015;31:1827-1834.

23. Zhuo H, Xu Y, Zhu F, Pan L, Li J. Osteochondral allograft transplantation for large Hill-Sachs lesions: A retrospective case series with a minimum 2-year follow-up. J Orthop Surg 2019;14:344.

24. Romeo AA, Cole BJ, Mazzocca AD, Fox JA, Freeman KB, Joy E. Autologous chondrocyte repair of an articular defect in the humeral head. Arthroscopy 2002;18:925-929.

25. Cuéllar A, Ruiz-Ibán MÁ, Cuéllar R. The use of allarthroscopic autologous matrix-induced chondrogenesis for the management of humeral and glenoid chondral defects in the shoulder. Arthrosc Tech 2016;5:e223-e227.

26. Lu Y, Dhanaraj S, Wang Z, et al. Minced cartilage without cell culture serves as an effective intraoperative cell source for cartilage repair. J Orthop Res 2006;24:1261-1270.

27. Fortier LA, Barker JU, Strauss EJ, McCarrel TM, Cole BJ. The role of growth factors in cartilage repair. Clin Orthop Relat Res 2011 ;469:2706-2715.

28. Frisbie DD, Lu Y, Kawcak CE, DiCarlo EF, Binette F, McIlwraith CW. In vivo evaluation of autologous cartilage fragment-loaded scaffolds implanted into equine articular defects and compared with autologous chondrocyte implantation. Am J Sports Med 2009;37(1_suppl):71-80.

29. Levinson C, Cavalli E, Sindi DM, et al. Chondrocytes from device-minced articular cartilage show potent outgrowth into fibrin and collagen hydrogels. Orthop J Sports Med 2019;7:232596711986761.

30. Lee KW, Moon KH, Ma CH, Lee GS, Yang DS, Choy WS. Clinical and radiologic outcomes after medializing and not medializing rotator cuff tendon attachment site on chronic retracted rotator cuff tears. Arthroscopy 2018;34:2298-2307.

31. Liu J, Hughes RE, O'driscoll SW, An K-N. Biomechanical effect of medial advancement of the supraspinatus tendon. A study in cadavera. J Bone Joint Surg 1998;80: 853-859. 